\title{
From One Dimension to Three Dimensional Vault" —— The Current Situation of Chinese Language and Literature Course in Higher Vocational Colleges
}

\author{
Wulan Wang \\ Guangzhou Vocational College of Science and Technology China Guangdong 510550
}

Keywords: Chinese language and literature; Higher vocational dolleges; Present situation analysis; Countermeasures thinking

\begin{abstract}
Courses in Chinese language and literature is in Higher Vocational Colleges and universities set up a major courses and the cultivation of is students of Chinese language and literature theory, basic knowledge and basic skills, so as to publishing institutions, scientific research units to provide professional talents. However, with the development of economic and social, the rapid development of higher vocational colleges, majoring in Chinese language and literature should out of focus "one-dimensional partial to" the study of training objectives, but be expanded with application of three-dimensional dome "change, profession is about cultural heritage, designed industry knowledge and operating skills of combined compound talents.

At present, the higher vocational colleges of Chinese language and literature major in a large extent is mimicked the research-oriented universities open mode so as not to show higher vocational colleges training features, in the competition of future student employment process and undergraduate college students nor their own advantages. Therefore, the question that can be raised is: whether the Chinese language and literature major in higher vocational colleges should be consistent with the training mode of undergraduate colleges and universities? In fact, different types or levels of school, in the talent training objectives should be different or focused on. The Chinese language and literature major in higher vocational colleges should have their own unique positioning.
\end{abstract}

\section{Present Situation of Chinese Language and Literature Course in Higher Vocational Colleges}

At present, the Chinese language and literature course in higher vocational colleges is an important course for the relevant professional personnel training. However, although some achievements have been obtained in the training of relevant talents, it is not completely satisfied, and there are many problems. According to the author's investigation, higher vocational college Chinese language and literature course system is not very perfect, there is a course structure is not reasonable, pay attention to other research universities, the imitation and study, thus affecting the characteristics of higher vocational colleges. In the content of the course, also follow the research university, pay attention to the theoretical knowledge of learning, the formation of a one-dimensional partial to the training of personnel system. However, in reality, there is a gap between the cultivation of research universities and a research university, which makes the students, have no advantage in the course of employment, so that the students are in a disadvantageous position in the course of employment. In addition, the courses on, there is a lack of teachers team construction, professional teachers are fewer in number, lack of teachers, and the teaching style also lays particular stress on classroom indoctrination, the practice and application of strength.

Visible, the current higher vocational college Chinese language and literature course and the reality of the demand there is a certain gap, and the goal of training and the school's own characteristics are not consistent with the positioning. Therefore, it is necessary to realize the transformation of the Chinese language and literature course in higher vocational colleges. 


\section{Reasons for the Transformation of Chinese Language and Literature Course in Higher Vocational Colleges}

In view of the above phenomenon, we need to realize the transformation of the Chinese language and literature course in Higher Vocational colleges. Why to realize this kind of turn, can carry on the analysis from the following several angles:

The first is the characteristics of Higher Vocational colleges. Schools only identify their own positioning, in order to better find their own school characteristics. Higher vocational colleges should focus on the cultivation of practical talents, which needs to be combined with reality. Higher vocational colleges undoubtedly cannot blindly follow and imitate other high level of college education, the need to work hard in the training of applied talents. Higher vocational college education, need to uphold their own characteristics, in accordance with the actual needs of personnel training.

Second is the social and economic development of the real needs. In the process of social development, there is an eager demand for the demand of the applied talents. After entering the society, students should be able to adapt to the social, social and economic development needs, in practice to exercise their own, able to have a good operating capacity. At the same time, with the development of society as a whole reached qualities, humanistic culture decreased, higher vocational colleges as educational institutions will undoubtedly need to pay attention to person's humanities accomplishment, moral cultivation, so in order to better adapt to social demand [1]. With the development of economy and society, especially the expansion of college enrollment, great changes have been made in the employment channels of Chinese language and literature major. The employment of the professional should have a broader prospect, so do not be biased to theoretical knowledge, but to pay attention to the cultivation and education of multidimensional literacy. Economic society is a society which emphasizes ability, its ability to individual and group is not only strengthened, but also with the development of economy and Society. Talent needs are more comprehensive.

Third, the characteristics of Chinese language and literature. Higher Vocational College of Chinese language and literature course for the specialty which opened, but the professional should not academic culture, Chinese language and literature is only a skill, not like biology, physics, as a high operation adaptability of subjects. Chinese language and literature major is an important part of Chinese major. Therefore, in the course of the construction process, the need to highlight the professional characteristics. Do not deviate from the theoretical side, and the other should not be effective skills training. This is harmful to the training of professional talents.

\section{The Transformation Strategy of Chinese Language and Literature Course in Vocational Colleges}

So, what kind of changes should be realized in the Chinese language and literature course in Higher Vocational Colleges? Is to withdraw from the traditional one dimensional partial to the ivory tower, out of a way to adapt to the economic and social needs of the application? The arrival of the so-called "one-dimensional partial to" is too pedantic, emphasis on theoretical knowledge learning and education, and the application type can be summarized as "three vaults, namely humanities accomplishment, professional theory, professional skill three dimensions balance teaching and enable students to achieve the three" society ", namely" how to behave "," learning to do "," how to develop "[2]. These three "learn" and the three dimensions are not only unified, but also cross sensing, mutual support and mutual infiltration. Humanities accomplishment is the foundation, the professional theory is the condition, and the professional skill is the actual application. The "three vault" is to realize the transformation of culture to practical talents, in order to better adapt to the change of social development. To this end, the Chinese language and literature course in higher vocational colleges should adapt to the change, and make the corresponding adjustment. The core competitive power of the "three dimensional vault" teaching system is embodied in two aspects:

First, compared with the traditional mode of running school, the teaching mode is based on the 
humanistic and theoretical knowledge, while ignoring the operation skills, which is transformed into the humanistic foundation, direction theory and operation skills. This and the cultivation of Research University compared, Higher Vocational College of Chinese language and literature course will highlight the practical skills culture, emphasizes the humanities background, highlighting the personnel training, multi dimension integrated.

Compared with the second, and specialist, by only focus on skills training, despise secretarial theory, ignoring humanities, so a "technology, light principle, suddenly the" mode into "humanities, science, skills" 3D both. College is too much emphasis on practice, while ignoring the cultivation of theory and literacy. Specialization, skill, and the current higher vocational college Chinese language and literature should be avoided. In professional schools and social demand, there is always a tension, too eager to meet the social demand will likely lead to the vulgarization of the education.

Therefore, in comparison to the research universities and colleges, the "three dimensional vault" of the Chinese language and literature in higher vocational colleges is a middle road, which is a proper balance between theory and practice, and is not a waste of the two. The theory of learning and practice skills training, foundation and rich cultural foundation on the basis of specific to the Chinese language and literature courses in higher vocational colleges, we can think of transformation from the following perspectives:

One, to strengthen the construction of the relevant curriculum system, modifies the current theory of teaching the course, rich humanities courses and practical courses. This is to form a relatively complete knowledge structure, curriculum system. To lay a solid foundation for the training of talents. Construction of curriculum system is a difficult task, Chinese language and literature course in higher vocational colleges need comprehensive school is some characteristics or expertise, formed a relatively complete curriculum system, based on all aspects of the 3-D vault, optimize the curriculum system.

Second, pay attention to the construction of the teaching staff. In the recruitment of personnel to pay attention to the comprehensive assessment of the quality of teachers, the structure of the team to be integrated into consideration, the formation of a more reasonable age structure. Encourage teachers to carry out practical teaching, in the course of teaching the importance of humanistic quality. Learning to comprehensive consideration of humanities courses, the Chinese language and literature courses related to the humanities to enhance the quality of the humanities, internalized into the humanities.

Third, to encourage students to carry out related practice. Higher vocational colleges should attach importance to students' social practice, through participation in extracurricular activities in professional practice, athletic events such as, enrich the connotation of curriculum of Chinese language and literature, and urge the student's skills in practice exercise. Schools to build relevant internship training platform, so that students in a wide range of practical operation, enhance the professional skills. For the Chinese language and literature, most of the time is engaged in secretarial work, and secretarial work in various industries has a many of the reality of the situation, only rely on the teaching of the course is cannot achieve the purpose of training the talents, the actual participation in exercise.

Fourth, pay attention to students' humanistic quality inspection. In the evaluation system of students, we should gradually highlight the proportion of students' humanistic quality, comprehensive study of the overall quality of students, the investigation into the rewards and punishments mechanism of Higher Vocational colleges. The humanistic moral quality of students can be quantified in the appropriate circumstances, so as to enhance the status of humanities literacy in the curriculum system, but also to master the effect of school personnel training.

Anyway, the transformation of the Chinese language and literature course in higher vocational colleges is to adapt to the needs of social and economic development, is showing the characteristics of Higher Vocational Colleges' personnel training needs, is in the new period of comprehensive qualities of talents cultivation of strategic thinking. Combined with the Chinese language and literature course in higher vocational colleges, it is necessary to deepen the practice teaching, and to highlight the comprehensive balance development of humanistic qualities, theoretical knowledge 
and professional skills.

\section{References}

[1] Zhang Tingkai. An analysis on the construction of Chinese language and literature courses in Higher Vocational Colleges [J]. The Yalu River (the second half of the Second Edition), 2015, 3:829.

[2] Gao Wei, Zhang Huaqing, Qin Jingli, Qu Xizhen. New media from the perspective of Higher Vocational Colleges literature appreciation curriculum present situation and reform thinking [J]. Science magazine, 2015, 16:7.

Author Introduction:

Hohhot Inner Mongolia people, Inner Mongolia University, Guangzhou Vocational College of Science and Technology, lecturer, research direction: Chinese language and literature, vocational education 